\title{
Influence of Galactic and Solar Cosmic Rays on Ionization in the Atmosphere
}

\author{
Umahi, A.E. \\ Department of Industrial physics (Astrophysics unit), Faculty of Science, Ebonyi State University, Abakaliki, \\ Nigeria.
}

\begin{abstract}
A comprehensive review of the influence of Galactic and Solar Cosmic Rays (GSCRs) in the Earth's atmospheric is hereby presented. The results of the characterizations of the GSCRs (measured in counts) and AST (measured in ${ }^{\circ} \mathrm{C}$ ) against Time (measured in hours) shows significant variations. The positive correlation coefficient, $\boldsymbol{r}$ between GSCRs and ASTs, ranging from 0.020 to 0.800 also shows that the events of GSCRs gives rise to ASTs in the earth's atmosphere. The low level of $\boldsymbol{r}$ in these result indicates that other solar activities such as sunspot, coronal mass ejection and solar wind directly enters the Earth's atmosphere, while the high level of $\boldsymbol{r}$ shows that the GSCRs is responsible for the ASTs. The large number of references up to 118 is a source for scholars' interest in the various contribution of space research.
\end{abstract}

Key Words: Cosmic Rays, Solar flar, Ionization and Solar Activity.

\section{Introduction}

The influence of Galactic and Solar Cosmic Rays (GSCRs) to generate ionization and produce nuclearelectromagnetic cascade which enhances the variation of average surface temperature in the earth's atmosphere cannot be over emphasized. The enhance hazard of these variations to astronauts, communication, human DNA is highly debated globally [1]. The main origin of GSCRs are from outside and within our solar system. The sun is the driving source within our solar system for Galactic Solar Cosmic Rays (GSCRs) were sporadic particles are release into space during solar flares(SFs). SFs are high energy protons. Whereas, the Galactic Cosmic Rays (GCRs) are high energetic particles from outside our solar system. The GCRs consist also of high energy proton and heavy ions origin. The composition of this primary GSCRs are proton $(\sim 10 \%)$ and electrons $(\sim 1 \%)$. The increase rate of ionization that takes place in the earth's atmosphere is the most dangerous emissions from this radiations, including protons, $\mathrm{x}$ - rays and ultraviolent radiations (UV). In spite of these, they continuous monitoring of the Earth's atmospheric ionization remains unlimited for astronomers, astrophysics and space scientist globally $[2,3]$.

The naked Eye observation shows confusing climatic variation as the time rolls. These led to initial design and construction of early Balloon experiments used in the past to measure the induced ionization at different locations and during solar cycles [4,5,6,7,8], Rockets [9], Spacecraft [9, 10], Muon telescope [11],Neutron monitor data and Cherenkov counter measurements at high mountain altitude [12] and Ground base observatory networks[13].

The creation of independent galactic charged particles interaction at the D-region of the Earth's atmosphere ranging from 50 to $100 \mathrm{~km}$ above the sea level have been identified[14,15,16]. Furthermore, above $100 \mathrm{~km}$ altitude, the contributions of the electromagnetic, $\mathrm{x}$-rays and ultraviolent radiation dominates [16]. Based on these, the particles influences the ionization, chemical and electrical conditions in the atmosphere ranging from 5 to $100 \mathrm{~km}$. In contrary, near the Earth's surface which is below $5 \mathrm{~km}$, an additional source of ionization occurs via natural radioactivity of the soil may introduce radon gas emission in some regions [17].

Several authors have studied and published papers on GSCRs forclarifications as follows:Origin of Cosmic Rays [18, 19, 20, 21]; Cosmic Rays in the Earth's Atmosphere[22, 23]; Cosmic-ray propagation in the atmosphere [24];Solar and Galactic Cosmic Rays in the Earth's Atmosphere[25,26];Protons and Heliumspectra compositions of cosmic rays [27,28,29, 9, 30,31,32,33];Cosmic ray and solar protons induced ion and ionization production in the atmosphere and its influence on ozonosphere[34,35,36,37, 38, 39,40, 14, 41, 42, 43,44,45, 46],Ionization profiles caused by galacticand solar cosmic rays[47];Ratio of solar cosmic ray ion generation[47,48]; Global atmospheric electrical circuit on climate and Solar windcontrol[49,50,51,52,53,54,55,56,57,58,59,60,61,62, 7];Production of atomic nitrogen and oxygen by relativistic proton impact in air[63,64];Rate of electron production in ionosphere by cosmic rays[65,66,67];Calculation ofelectron production rate profiles[68];Determinationof electron production rates caused by cosmic ray particlesin ionospheres of terrestrial planets [69];Influence of galactic cosmic rays on atmospheric composition and dynamics[70,71]; Galactic cosmic ray influence on climate and ozone variations [72,73,74,75,76,77,78,79]; Atmospheric profiles on extensive air shower observation [80,81,82], Empirical and approximation model of cosmic ray spectrum in energy[83, 84,],Analytical model forcosmic ray ionization by 
nuclei with charge $\mathrm{Z}$ in the lowerionosphere and middle atmosphere,[85,86], Simulation and Chemistry-climate modeling[87,88,89,90,91]; Model for inducedionization by galactic cosmic rays in the Earth atmosphere and ionosphere (Velinov et al., 2009; Wissing and Kallenrode, 2009),Simulation of cosmicray ionization profiles in the middle atmosphere and lowerionosphere [92];Newoperational models for cosmic ray ionization in space [93]; Improved cosmic rayionization model for ionosphere and atmosphere[94];Progress in space weather modeling in an operational environment [95];Code for computing the interaction of cosmic rays with the Earth's atmosphere [96];Anomalous cosmic-ray component of singly ionization[97, 98,99,100]; Cosmic ray induced ionization in the atmosphere with CORSIKA code simulations [101,102]; Solar cosmic ray induced ionization in the Earth's atmosphere with CORSIKA code simulations [103], Energy interval coupling in improved cosmic ray ionization model with three intervals in ionization losses function for the system atmosphere/ionosphere $[104,105]$.The contribution of this work will focus on theinfluence of galactic and solar cosmic rays on ionization in the atmosphere where the index particles are cosmic rays and solar flares. These particlesaffect the variations of atmospheric phenomena such as average surface temperature (AST). The main procedure used in this work is to statistically analysis the hourly variations of percentage (\% GSCR) and percentage (\% AST) in the earth's atmosphere applying excel programs.

\section{Atmospheric Galactic Cosmic Ray Ionization}

The primary galactic cosmic rays (GCRs) initiate a nucleonic-electromagnetic cascade at altitudes below $30 \mathrm{~km}$ in the atmosphere, with the main energy losses which results in ionization, dissociation and excitation of molecules (Dorman 2004). The full Monte-Carlo CORSIKA (Cosmic Ray SImulations for KAscade) simulation were used for modelling the atmospheric nucleonic-electromagnetic cascade [98]. The development of COST-724 action (2003-2007) which led to discovery of three numerical GCRs ionization models[25, 26].The Sofia model which worked for an analytical approximation of the direct ionization by GCR primaries above $30 \mathrm{~km}[85,106,107]$ as well as the CORSIKA Monte-Carlo package extended by FLUKA package to simulate the low-energy nuclear interactions below $30 \mathrm{~km}[86,31,82]$. The Oulu CRAC (Cosmic Ray Atmospheric Cascade) model which is based on the CORSIKA/FLUKA Monte-Carlo simulationsaccount for direct ionization by primary GCR particles $[108,25,26]$.

The Bern model (ATMOCOSMICS/PLANETOCOSMICS code) is based on the GEANT-4 MonteCarlo simulation package[87]. The main contribution was obtained by Desorgher et al. (2005) and Schereret al. (2007),[25,26], etc. The codes of CORSIKA and GEANT-4confined study of the cascade evolution in the atmosphere.The simulation of the interactions and decays of various nuclei, hadrons, muons, electrons and photons resultedin the detailed information of the type, energy, momenta, location and arrival time of the produced secondary particles at given selected altitude above sea level $[25,26]$.

In contrast to the lower atmosphere, theyis ionization of the middle and upper atmosphere and the cascade could not be well developed. Based on these poor interactions to engineer the cascade, a relatively simple analytical solution was applied using model CORIMIA (Cosmic Ray Ionization Model for Ionosphere and Atmosphere) for cosmic rays ionization above $30 \mathrm{~km}$ [109]. Considering the fact that the atmospheric depth at the altitude of $30 \mathrm{~km}$ is about $10 \mathrm{~g} / \mathrm{cm}^{2}$ at $500 \mathrm{~km}$, which is much less than the nuclear free path of protons and a particles of about 70 and $30 \mathrm{~g} / \mathrm{cm}^{2}$ respectively. Theyconsidered only ionization losses of the primary cosmic ray particles and neglected nuclear interactions in the middle atmosphere above $30 \mathrm{~km}$ (upper stratosphere and ionosphere) [14,26];: In addition, they further neglect changes of energetic particles for the altitude above 50 $\mathrm{km}$, thus, reducing the computation of cosmic ray ionization to an analytical thin target model $[65,67,68]$. At the altitude ranging from 25-30 to $50 \mathrm{~km}$, an intermediate target model needs to be applied which accounts for the particle's deceleration due to ionization losses [66]. This model was also used for the calculation of electron density and atmospheric electrical conductivities in the middle atmosphere for different particles: Galactic Cosmic Rays (GCRs), Anomalous Cosmic Rays(ACRs) and Solar Energetic Particles (SEPs)[109].An intermediate target ionization model was added to account for the Chapman function values for the penetrating particles in the spherical atmosphere [110,111]. The program CORIMIA was discovered for the calculation of the electron and ion production rate profiles due to cosmic rays using ionization losses (Bohr-Bethe-Bloch function) approximation in six characteristic energy intervals, which includes the charge decrease interval for electron capturing $[93,117,118]$. The detailed model for calculation of CR ionization rates which is the number of electron-ion pairs in $\mathrm{cm}^{-3}$ per second at given altitude in the ionosphere and middle atmosphere[16]. The mathematical expression of the fully operational program CORIMIA is detailed in Velinov 1966.The contributions to the expression ofionization losses [118] of particles and the charge of the nuclei( $(\mathrm{Q}=35 \mathrm{eV})$ which was the energy necessary for theformation of one electron-ion pair [63].

Model CORIMIA computed the cosmic ray ionization profiles at a given location and time, solar and geomagnetic activity. The calculations were done in the cusp (that is, a pointed end where two curves meet) region $(\mathrm{Rc}=0 \mathrm{GV})$ at different altitudes ranging from30-120 km. Observation showed that these are the maximum values of ionization in the atmosphere of the Earth. The results for ionization rate profiles for the 
different groups of galactic cosmic rays (GCRs) nuclei and GCRs ionization profile at minimal solar activity are shown in Fig.1. Thus, the total ionization rate of Fig.1Bcompose of the ionization rates from main groups of the GCRs nuclei: protons, Helium (a particles);Light and Medium shown in Fig.1A;and, Heavy and Very Heavy presented in Fig. 1B. The ionization profiles which are shown in Fig.1A and 1B show the maximal ionization in the Earth's ionosphere and atmosphere[16]. The computational resultsof computer algebra system, version 7.0 are obtained(Wolfram, Mathematic 2008).

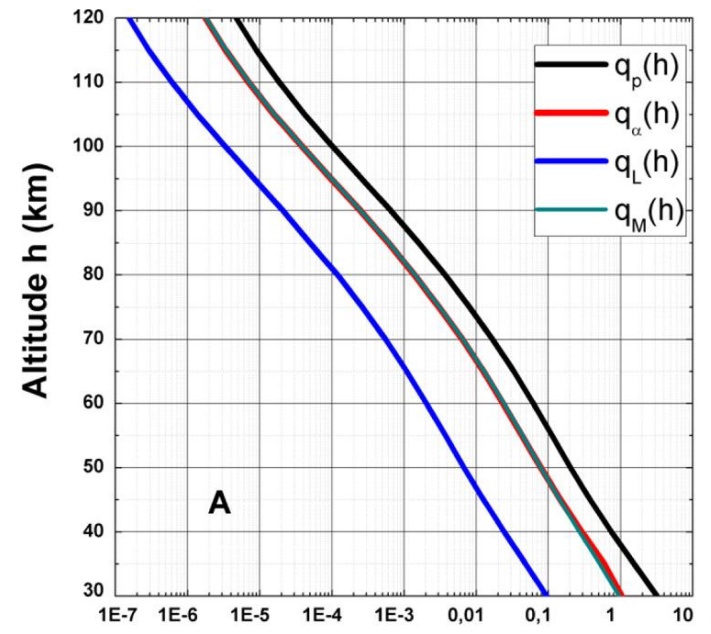

Electron production rate $\mathrm{q}(\mathrm{h})\left(\mathrm{cm}^{-3} \mathrm{~s}^{-1}\right)$

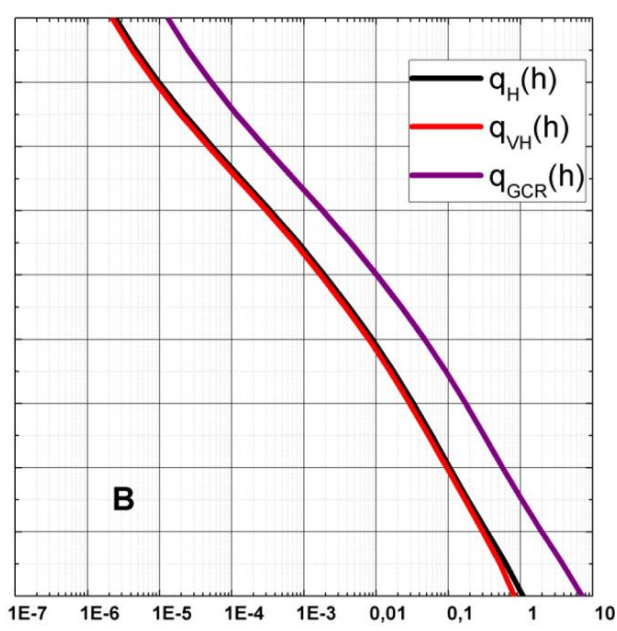

Electron production rate $q(h)\left(\mathrm{cm}^{-3} \mathrm{~s}^{-1}\right)$

Fig.1. Electron production rate $\mathrm{q}(\mathrm{h})$ profiles due to GCRs in cusp region for $\mathrm{A}: \mathrm{p}, \mathrm{a}, \mathrm{L}$ and $\mathrm{M}$ groups of nuclei, and $\mathrm{B}: \mathrm{H}$ and $\mathrm{VH}$ groups of nuclei and the total GCRs ionization during minimal solar activity[115].

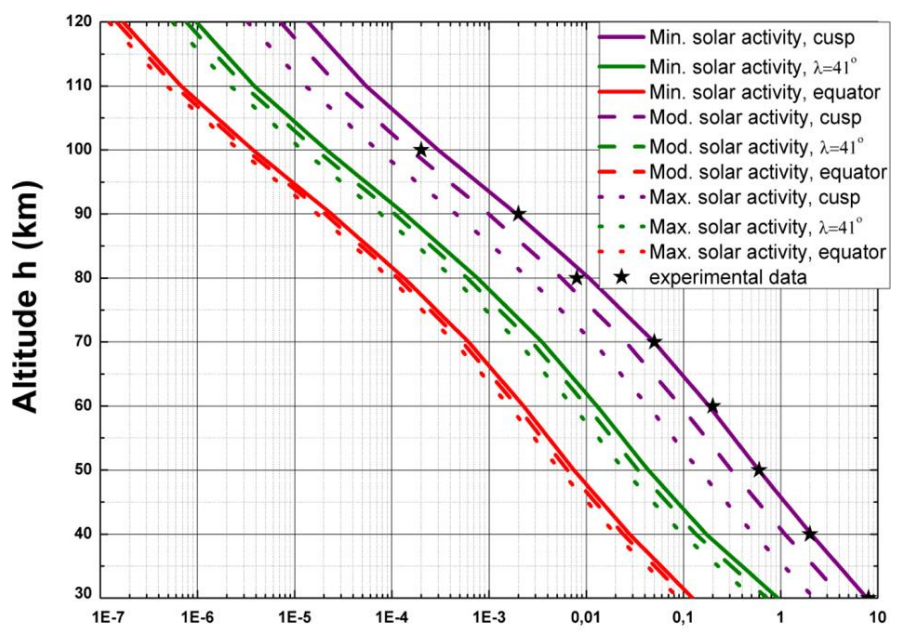

Electron production rate $\mathrm{q}(\mathrm{h})\left(\mathrm{cm}^{-3} \mathrm{~s}^{-1}\right)$

Fig. 2. Electron production rate $\mathrm{q}(\mathrm{h})$ profiles due to GCR for cusp, middle latitudes $\left(\mathrm{k}=41_{-}\right)$and equator at minimal, moderate and maximal solar activity. Experimental data $(*)$ are taken from Brasseur \& Solomon (2005); [116][16].

The calculations which give a decrease of the ionization rates with the latitude as shown in Fig. 2 may be attributed to theincrease of geomagnetic cut-off rigidity from geomagnetic poles $(\mathrm{Rc}=0 \mathrm{GV})$ to the geomagnetic equator $(\mathrm{Rc}=15 \mathrm{GV})$. In Fig. 2are presented results for electron production rate profiles for cusp (geomagnetic latitude $\mathrm{k}=90)$, middle latitudes $(\mathrm{k}=41)$ and equator $(\mathrm{k}=0)$ at minimal, moderate and maximal solar activity. Experimental data $(*)$ from rocket measurements $(40-100 \mathrm{~km})$ are considered [116]. The influence of solar wind modulation into the GCR causes the atmospheric ionization decreases with growth of solar activity [16].

\section{Data, Methods And Result Analysis}

The data used in this work are downloanded from observatories of Mexico for cosmic ray data, Space Physics Interactive Data Resources (SPIDR) and National Space Research and development Agency, (NASRDA), Anyiba, Nigeria; for cosmic rays, solar flare and average surface temperature respectively for the 
year 2010 respectively. These data were collected in hourly intervals for a month. These data of about $720 \mathrm{hrs}$ per month for 12- months events were arranged in four different groups in an excel spread sheets were they are statistically analyzed and used in this paper. In each of the group, the percentage of accommodation of galactic cosmic rays (\%GCR), galactic solar flare (\%GSF) and average surface temperature (\%AST)in the earth's atmosphere were computed hourly and considered. Then, \%GCR and \%GSF were summed to a single source of percentage of galactic and solar cosmic rays (\%GSCR,that is, \%GCR + \%GSR $=\% \mathrm{GSCR})$.

The group is the characterization of $\% \mathrm{GSCR}$ and $\% \mathrm{AST}$ (measured in count) against time (measured in hour)which represented January, February and March as shown in Fig.3. The process were repeated which represents the second thatcovered the events of April, May and June as shown in Fig.4., the third which covered the events of July, August and September as shown in Fig.5 and the fourthgroup which represents the activities of October, November and December as shown in Fig.6. Theduration of the time ranges from a maximum of $0.744 \times 10^{2} \mathrm{hr}$ to $0.768 \times 10^{2} \mathrm{hr}$ as the numbers of days in the month varies.

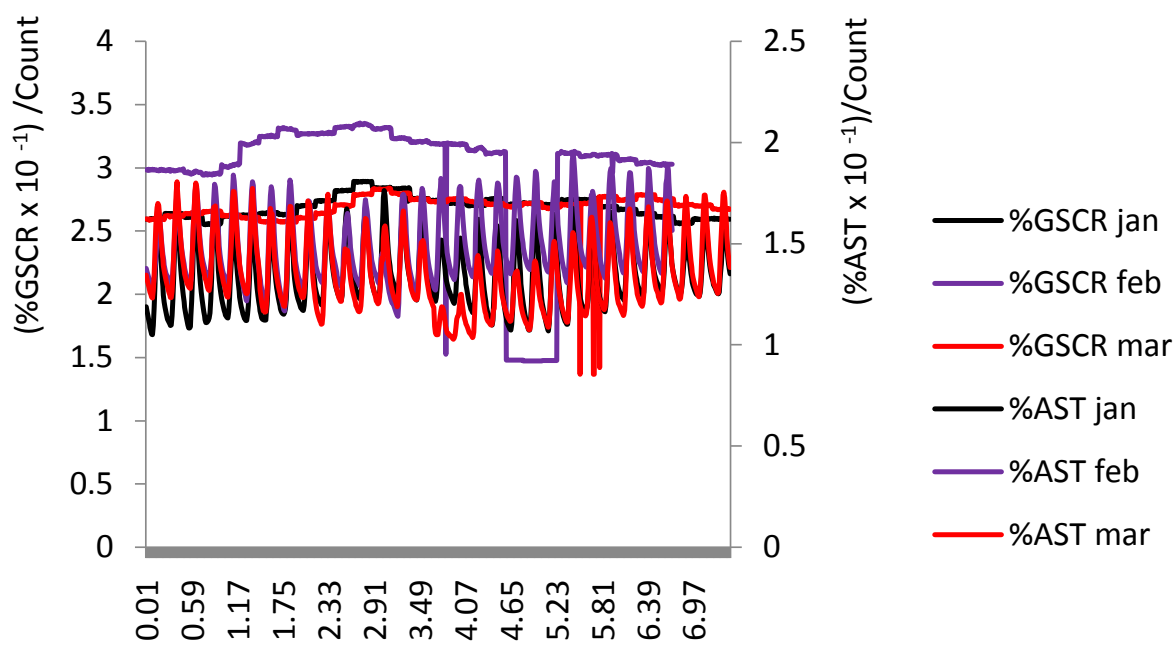

(Time $\left.\times 10^{2}\right)$ /hour

Fig.3.Variations of percentage Galactic and Solar Cosmic Rays (\%GSCR) and percentage Average Surface Temperature (\%AST) (measured in count) against Time (measured in hour). The legend colour for \%GSCR and \%AST: the month of January is black; the month of February is blue and the month of March red.
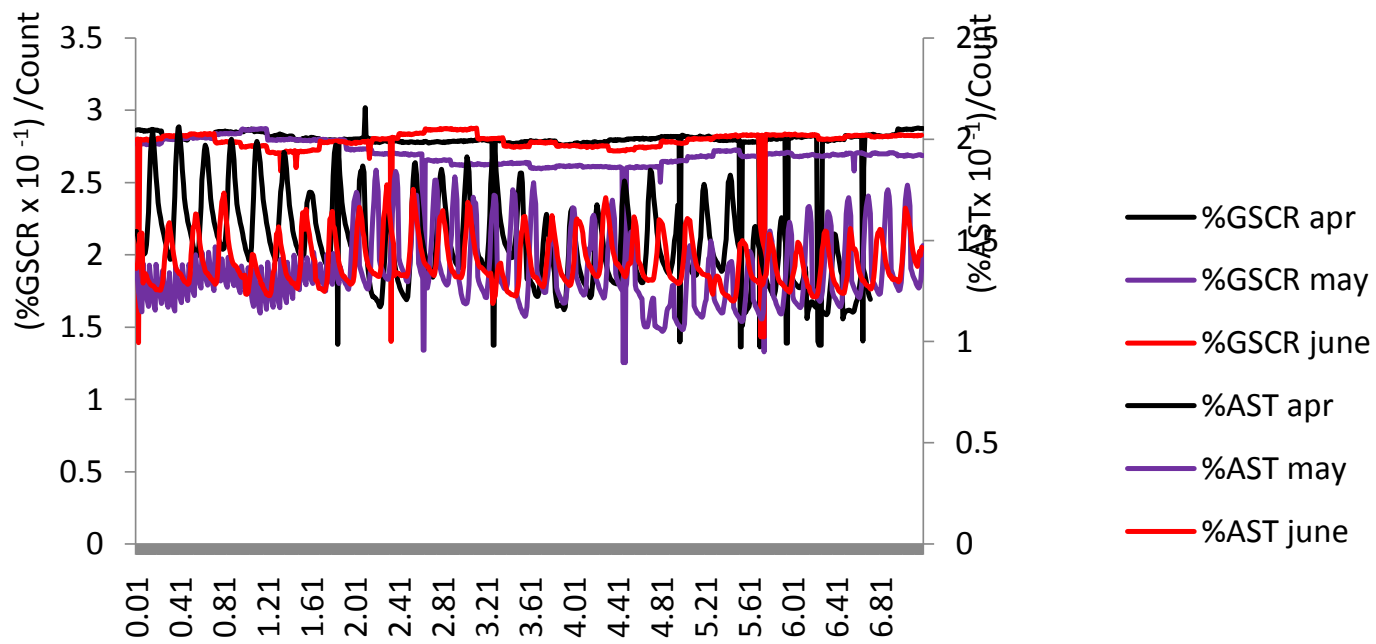

(Time $\left.\times 10^{2}\right)$ /hour

Fig.4. Variations of percentage Galactic and Solar Cosmic Rays (\%GSCR) and percentage Average Surface Temperature (\%AST) (measured in count) against Time (measured in hour). The legend colour for \%GSCR and $\%$ AST:the month ofApril is black; the month ofMay is blue andthe month ofJune is red. 


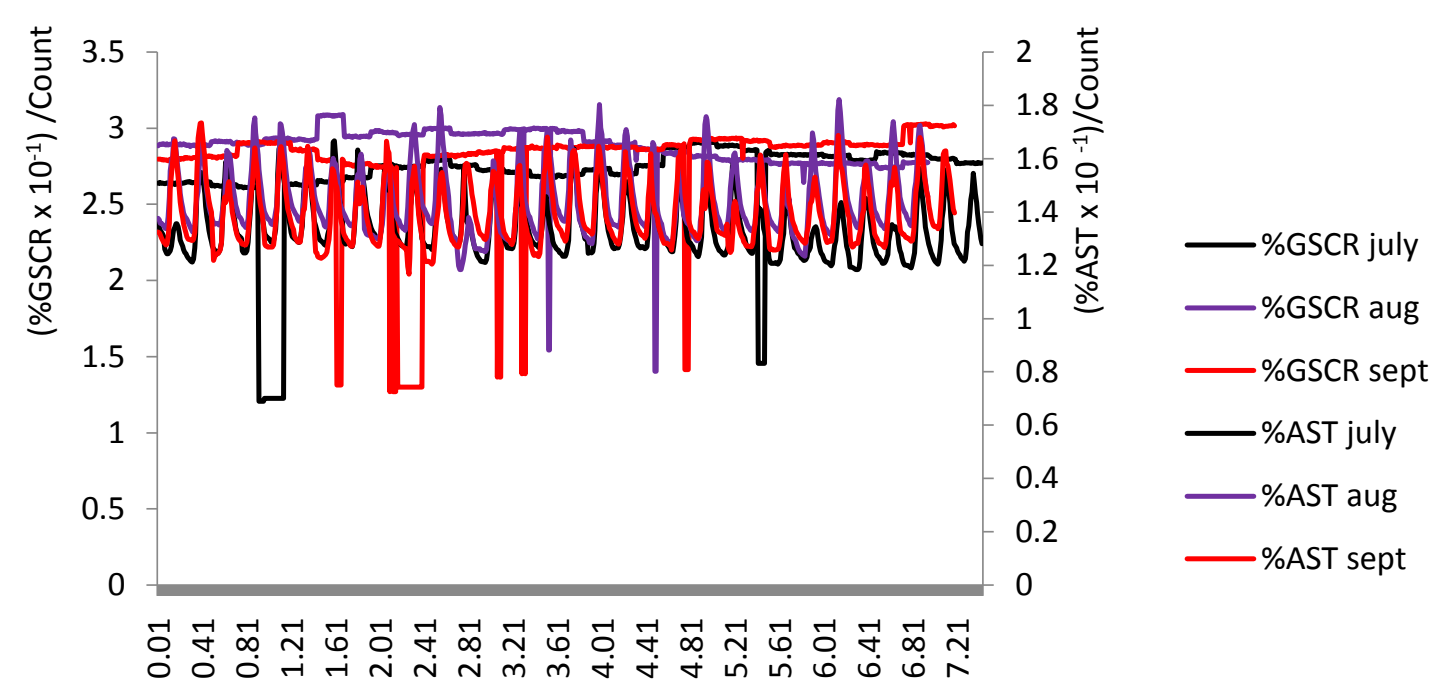

$\left(\right.$ Time $\left.\times 10^{2}\right) /$ hour

Fig.5 Variations of percentage Galactic and Solar Cosmic Rays (\%GSCR) and percentage Average Surface Temperature (\%AST) (measured in count) against Time (measured in hour). The legend colour for \%GSCR and \%AST:the month ofJuly is black; the month ofAugust is blue andthe month of September is red.

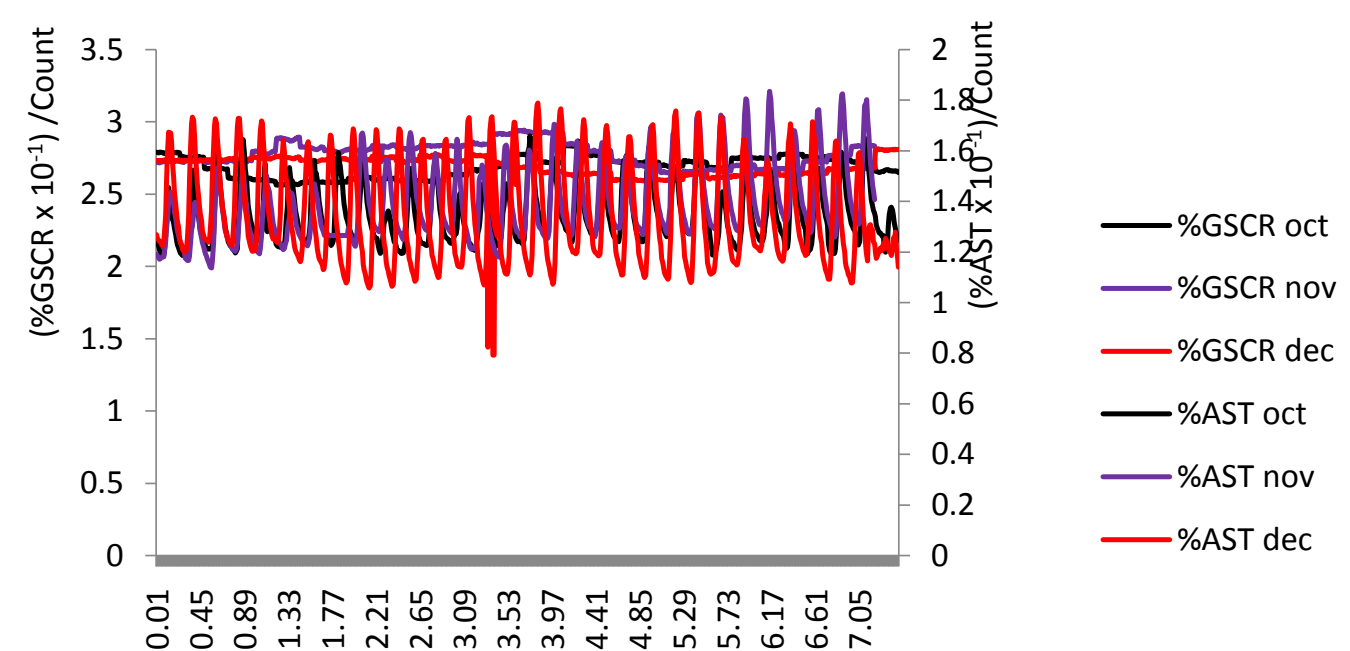

(Time $\left.\times 10^{2}\right)$ /hour

Fig.6. Variations of percentage Galactic and Solar Cosmic Rays (\%GSCR) and percentage Average Surface Temperature (\%AST) (measured in count) against Time (measured in hour). The legend colour for \%GSCR and $\%$ AST:the month ofOctober is black; the month ofNovemberis blue andthe month of December is red.

In addition to the above characterizations, a correlation analysis of excel program were carried out in order to ascertain the level of relationship between GCRs and SCRs. The results of the correlation coefficient, r, ranges from 0.020 to 0.800 .

\section{Discussion And Conclusions}

The data shown in the characterization from figures 3 to 6 , indicates that the $\%$ GSCR and \%AST intensity during a given month are uniquely related. This is precisely what would be expected in this work. The magnitude of the effect of \%GSCRvary with atmospheric regions. The \%GSCR and \%AST intensity observed on the earth's atmosphere are dependent on the distribution of interactions in the earth's atmosphere over a long scale of time. The results of the statistical study in this work showed significant characterization with respect to hourly sample variations. The \%GSCR and \%AST showed a continuous variation with time (measured in hour). This variations are in agreement with some authors [26, 115;112,113,114]. 
The variations of fig. 3 showed the event of \%GSCR and \%AST in January, February and March. Fig.4 showed the event of\%GSCR and \%AST in May, June and April. Fig.5 showed high variations of \%GSCR and $\%$ AST in July, August and September. Fig.6 showedvariations of \%GSCR and \%AST in October, November and December.

The correlation coefficients, $r$ between GCRs and GSFs are positive correlation, ranging from 0.020 to 0.800 . The positive correlation coefficient is in agreement with other authors $[26,16,111,112,113,114]$.

In conclusion, the observatory stations exploring the earth's atmosphere records measurements of GCRs, GSFs and ASTs on hourly events for the year, 2010. The GCRs and GSFs are combined as a single source of GSCRs. The measurements are interpreted on an excel spread sheet statistically. The percentage of accommodation of GSCRs and ASTs are determined.The graphical analysis showed that they are presents of $\%$ GSCR and \%ASTin the earth's atmosphere. The hourly variation of GSCRs indicates a continuous arrival of events with variation in amplitude. Finally, the positive correlation coefficient found in theseresults show that the variation GSCRs events gives rise to the variation of AST.

\section{Acknowledgement}

The author is grateful to the contributions of Mr. Okpaga Afamefuna M., Mr. Uda Callistus N., Mr. Ukoji Nnanna, U., Mr. Nwuzor Ogochukwu C., Mr. Nwogwu Chisom J. and Mr. Eze Tochukwu, S.M. Finally, to my wife (Mrs. Lilian C. Umahi) and my children (Chidera, Sopuruchukwu, Kasiemobi, Ugochukwu and Chukwuebuka), for accommodating my long absence in the home during the pursuit of this work.

\section{Reference}

[1]. Umahi, A.E,(2016). Galactic and Solar Cosmic Rays on Ionization in the Atmosphere, World Applied Science Journal, 34 (3), $312-$ 317, DOI: 10.5829/idosi.wasj.2016.34.3.15660.

[2]. Tinsley, B.A.,(2000). Influence of solar wind on the global electric circuit, and inferred effects on cloud microphysics, temperature, and dynamics in the troposphere, Space Sci. Rev., 94 (1-2), 231-258.

[3]. Singh, A. K., D. Singh, and R. P. Singh, (2011), Impact of galactic cosmic rays on Earth's atmosphere and human health, Atmos. Environ., 45, 3806-381188,

[4]. Bazilevskaya, G.A., 2000. Observations of Variability in Cosmic Rays, Space Sci. Rev.,94, 25-38.

[5]. Neher, H.V., 1971. Cosmic rays at high latitude and altitudes covering four solar maxima, J. Geophys. Res., 76, 1637-1651.

[6]. Lowder, W.M., Raft,P.D., and Beck, H.L., 1972. Experimental determination of cosmic-ray charged particle intensity profiles in the atmosphere, in: Procs. National Symp. on Natural and Manmade Radiation in Space (Eds. E.A. Warman), Las Vegas, 1971, NASA, 908-913.

[7]. Rosen, J.M., Hofmann,D.J., and Gringel, W., 1985. Measurements of ion mobility to 30 km, J. Geophys. Res.,90(D4), 5876-5884

[8]. Ermakov, V.I., Bazilevskaya, G.A., Pokrevsky, P.E., Stozhkov, Yu.I. 1997. Ion balance equation in the atmosphere. J. Geophys. Res.,102(D19), 23413-23419.

[9]. Burger, R.A., M.S. Potgieter, and Heber, B.,(2000). Rigidity dependence of cosmic ray proton latitudinal gradients measured by the Ulysses spacecraft: implications for the diffusion tensor, J. Geophys. Res., 105, 27447.

[10]. Shea, M.A., Smart, D.F., 1996. Overview of the effects of solar-terrestrial phenomena on man and his environment. Nuovo Climento 19c (6), 945-952.

[11]. Braun, I., Englerm,J., Horandel,J.R., Milke,J., (2005). Solar modulation of cosmic rays in the energy range from 10 to 20 GeV, $29^{\text {th }}$ International Cosmic Ray Conference Pune 2, 135-138.

[12]. Mishev, A., (2010). A study of atmospheric processes based on neutron monitor data and Cherenkov counter measurements at high mountain altitude, J. Atmos. Sol. Terr. Phys., 72 (16), 1195-1199,.

[13]. Umahi, A.E,(2016). Earths Environmental Pollution from Galactic Cosmic Rays Flux, World Applied Science Journal, 34 (3), 338 342, DOI: 10.5829/idosi.wasj.2016.34.3.15659.

[14]. Velinov, P.I.Y.,(1974). Cosmic ray ionization rates in the planetaryatmospheres, J. Atmos. Terr. Phys., 36, $359-362$.

[15]. Nestorov, G.,(1969). Physics of the Lower Ionosphere, Publ. House of the Bulg. Acad. Sci, Sofia,

[16]. Velinov, P.I.Y., Asenovski, S., Kudela, K., Lastovicka, J., Mateev, L., Mishev, A. and Tonev, P., (2013). Impact of Cosmic Rays and Solar Energetic Particles on the Earth's Ionosphere and Atmosphere, J. Space weatherspace clim.3(A14), pp:1-17.

[17]. Usoskin, I.G., G.A. Kovaltsov, I.A. Mironova, A.J. Tylka and W.F., (2011).Dietrich, Ionization effect of solar particle GLE events in low and middle atmosphere, Atmos. Chem. Phys., 11, 1979-1988.

[18]. Ginzburg, V.L., and Syrovatskii,S.I., (1964). The Origin of the Cosmic Rays, Pergamon Press, Oxford

[19]. Hillas, A.M., (1972). Cosmic Rays, Pergamon Press, Oxford.

[20]. Miroshnichenko, L.I.,(2001). Solar Cosmic Rays, ASSL, 260, Kluwer Academic Publishers, Dordrecht, Netherlands.

[21]. Miroshnichenko, L.I., (2008). Solar cosmic rays in the system of solarterrestrial relations, J. Atmos. Sol. Terr. Phys., 70, 450-466.

[22]. Dorman, L.I., (2004). Cosmic Rays in the Earth's Atmosphere and Underground, Kluwer Academic Publishers, Dordrecht.

[23]. Dorman, L.I., Kozin,I.D.,(1983). Cosmic Radiation in the Upper Atmosphere, Fizmatgiz, Moscow.

[24]. O'Brien, K., (1971). Cosmic-ray propagation in the atmosphere, Il NuovoCimento A, 3 (4), 521-547.

[25]. Usoskin, I., L., Desorgher, P.I.Y., Velinov, M., Storini, E., Flueckiger, R., Buetikofer, Kovalstov,G.A.,(2008). In Solar and Galactic Cosmic Rays in the Earth's Atmosphere. Developing the Scientific Basis for Monitoring, Modeling and Predicting Space Weather, editedby Lilensten, J., COST 724 Final Report, COST Office, Brussels, 127-135.

[26]. Usoskin, I, L. Desorgher, P.I.Y. Velinov, M. Storini, E. Flueckiger, R. Buetikofer, Kovalstov,G.A., (2009). Solar and galactic cosmic rays in the Earth's atmosphere, Acta Geophys., 57, (1/March), 88-101.

[27]. Alcaraz, J., B., Alpat, G., Ambrosi, H., Anderhub, L. A, et al.,(2000). Cosmicprotons AMS collaboration, Phys. Lett., B $490,27$.

[28]. Alcaraz, J.,B., Alpat,G.,Ambrosi,H., Anderhubag,L.A,et al., (2000). Heliuminnear Earth orbit AMS collaboratio, Phys. Lett., B 494, 193.

[29]. Boezio, M., P., Carlson, T., Francke, N., Weber, M., Suffert, et al., (1999). The cosmic ray proton and helium spectra between 0.4 and $200 \mathrm{GV}$, Astrophys. J., 518, 457. 
[30]. Menn, W., M. Hof, O. Reimer, M. Simon, A.J. Davis, et al., (2000). The absolute flux of protons and helium at the top of the atmosphere using IMAX, Astrophys J., 533, 281.

[31]. Mishev, A., and Velinov,P.I.Y., ( 2007). Atmosphere ionization due to cosmic ray protons estimated with CORSIKA code simulations, C.R. Acad. Bulg. Sci., 60 (3), 225-230.

[32]. Seo, E.S., Ormes, J.F., Streitmatter, R.E., Stochaj, S.J., Jones,W.V.et al.,(1991) Measurement of cosmic-ray proton and helium spectra during the 1987 solar minimum, Astrophys. J., 371, 763.

[33]. Shikaze, Y., Haino,S., Abe,K., Fuke,H., Hams, T. et al., (2007). Measurements of 0.2-20 GeV/n cosmic-ray proton and helium spectrafrom 1997 through 2002 with the BESS spectrometer, Astropart.Phys., 28, 154.

[34]. Krivolutsky, A., Kuminov, A. and Vyushkova, T.,(2005). Ionization of the atmosphere caused by solar protons and its influence on ozonosphere of the Earth during 1994-2003, J. Atmos. Sol. Terr.Phys., 67, 105-117.

[35]. Mishev, A., and Velinov,P.I.Y. (2009). Normalized atmospheric ionizationyield functions Y for different cosmic ray nuclei obtained with recent CORSIKA code simulations, C.R. Acad. Bulg. Sci., 62 (5), 631-640.

[36]. Mishev, A., and Velinov, P.I.Y., (2010). The effect of model assumptions on computations of cosmic ray induced ionization in the atmosphere, J. Atmos. Sol. Terr. Phys., 72, 476-481.

[37]. Mishev, A., and P.I.Y. Velinov, Renormalized ionization yield function Y for different nuclei obtained with full Monte Carlo simulations, C.R. Acad. Bulg. Sci., 64 (7), 997-1006,

[38]. Mishev, A., and Velinov, P.I.Y. (2011). Normalized ionization yield function for various nuclei obtained with full Monte Carlo simulations, J.Adv. Space Res., 48, 19-24, 2011 b.

[39]. Mishev, A., and Velinov,P.I.Y., (2012). Contribution of cosmic ray nuclei of solar and galactic origin to atmospheric ionization during SEP event on 20 January 2005, C.R. Acad. Bulg. Sci., 65 (3), 373-380.

[40]. Velinov, P.I.Y.,(1970). Solar cosmic ray ionization in the low ionosphere, J.Atmos. Terr. Phys., 32, $139-147$.

[41]. Velinov, P.I.Y., Nestorov,G., Dorman,L.(1974). Cosmic Ray Influenceon the Ionosphere and on the Radio-Wave Propagation, BAS Publ. House, Sofia.

[42]. Mishev, A., Velinov,P.I.Y.,Mateev,L., (2010). Atmospheric ionization due to solar cosmic rays from 20 January 2005 calculated with Monte Carlo simulations, C.R. Acad. Bulg. Sci., 63 (11), 1635-1642

[43]. Mishev, A., Velinov, P.I.Y., Mateev,L., Tassev,Y., (2011).Ionization effect of solar protons in the Earth atmosphere - case study of the 20 January 2005 SEP event, J. Adv. Space Res., 48, 1232-1237.

[44]. Mishev, A., Velinov, P.I.Y., Mateev, L., Tassev,Y., (2012). Ionizationeffect of nuclei with solar and galactic origin in the earth atmosphere during GLE 69 on 20 January 2005, J. Atmos. Sol.Terr. Phys., 89, 1-7.

[45]. Bazilevskaya, G.A., Usoskin,I.G., Fluckiger,E.O., Harrison, R.G., Desorgher,L. et al.,(2008). Cosmic ray induced ion production in theatmosphere, Space Sci. Rev., 137, 149-173.

[46]. Usoskin, I.G., Gladysheva,O.G.,Kovaltsov,G.A., (2004). Cosmic ray induced ionization in the atmosphere: spatial and temporal changes, J. Atmos. Sol. Terr. Phys., 66, 1791-1796.

[47]. Velinov, P.I.Y., (1968). On ionization in the ionospheric D region by galacticand solar cosmic rays, J. Atmos. Terr. Phys., 30, 1891-1905.

[48]. Butikofer, R., Fluckiger,E.O.,Desorgher, L., Moser,M.R.,(2008).The extreme solar cosmic ray particle event on 20 January 2005 and its influence on the radiation dose rate at aircraft altitude, Sci. Total Environ., 391 (2-3), 177-183.

[49]. Dorman, L.I., Krupitskaya,T.M., (1975). Calculation of expected ratio of solar cosmic ray ion generation speeds on different altitudes, in Cosmic Rays, Nauka, Moscow, 15, 30-33.

[50]. Bering III, E.A., Few,A.A.,Benbrook, J.R., (1998).The global electric circuit, Phys. Today, 51 (10), 24

[51]. Harrison, R.G., (2004.).The global atmospheric electrical circuit and climate, Sur. Geophys., 25 (5-6), $441-484$.

[52]. Markson, R., Muir,M., (1980). Solar wind control of the Earth's electric field, Science, 208, 979-990.

[53]. Olson, D.E., (1983).Interpretation of the solar influence on the atmospheric electrical parameters, in Weather and Climate Responses to SolarVariations, edited by B.M., McCormac, Assoc. Univ. Press, Boulder, CO, 483-488.

[54]. Rycroft, M.J., Israelson, S.,Price,C., (2000). The global atmospheric electrical circuit, solar activity, and climate change, J. Atmos. Sol.Terr. Phys., 62 (17-18), 1563-1576.

[55]. Rycroft, M.J., Odzimek,A.,Arnold, N.F., Fullekrug,M., Kulak, A., Neubert,T.,(2007). New model simulations of the global atmospheric electrical circuit driven by thunderstorms and electrified shower clouds: the roles of lightning and sprites, J. Atmos. Sol. Terr.Phys., 69, 2485-2509.

[56]. Tinsley, B.A.,(2012). A working hypothesis for connections between electrically-induced changes in cloud microphysics and storm vorticity, with possible effects on circulation, Adv. Space Res., 50, 791-805.

[57]. Tinsley, B.A., Zhou,L. (2006). Initial results of a global circuit model with stratospheric and tropospheric aerosols, J. Geophys.Res., $111, \mathrm{D} 16205$.

[58]. Tonev, P.T., Velinov,P.I.Y.,(2011). Model study of the influence of solar wind parameters on electric currents and fields in middle atmosphere at high latitudes, C.R. Acad. Bulg. Sci., 64 (12), 1733-1742.

[59]. Tinsley, B.A., Heelis,R.A., (1993). Correlations of atmospheric dynamics with solar activity: evidence for a connection via the solar wind, atmospheric electricity, and cloud microphysics, J. Geophys. Res., 98, 10375-10384.

[60]. Velinov, P.I.Y., Tonev,P., (2008). Electric currents from thunderstorms tothe ionosphere during a solar cycle: quasi-static modeling of thecoupling mechanism, J. Adv. Space Res., 42, 569-1575.

[61]. Weimer, D.R., flexible,A.,(1996). IMF dependent model of high latitudeelectric potential having "space weather" applications, Geophys.Res. Lett., 23, 2549-2552.

[62]. Williams, E.R.,(2009). The global electrical circuit: a review, Atmos. Res.,91, 140-152.

[63]. Porter, H.S., Jackman,C.H., Green,A.E.S., (1976). Efficiencies for production of atomic nitrogen and oxygen by relativistic proton impact in air, J. Chem. Phys., 65, 154-167.

[64]. Vitt, F.M., Jackman, C.H., (1996). A comparison of sources of oddnitrogen production from 1974 through 1993 in the Earth's middleatmosphere as calculated using a two-dimensional model, J.Geophys. Res., 101, 6729-6740.

[65]. Velinov, P.I.Y.,(1966). An expression for ionospheric electron productionrate by cosmic rays, C.R. Acad. Bulg. Sci., 19 (2), 109112.

[66]. Velinov, P.I.Y., (1967). Some results of the rate of electron production in thecosmic layer of low ionosphere, C.R. Acad. Bulg. Sci., 20 (11),1141-1144.

[67]. Velinov, P.I.Y., (1967). On electron production rates in the polar capionosphere due to solar cosmic rays, C.R. Acad. Bulg. Sci., 20(12), 1278-1278.

[68]. Velinov, P.I.Y., Mateev,L., (2008). Improved cosmic ray ionizationmodel for the system ionosphere - atmosphere. Calculation ofelectron production rate profiles, J. Atmos. Sol. Terr. Phys., 70,574-582. 
[69]. Velinov, P.I.Y., Buchvarova,M., Mateev,L., Ruder,H.,(2001). Determinationof electron production rates caused by cosmic ray particlesin ionospheres of terrestrial planets, J. Adv. Space Res., 27 (11),1901-1908.

[70]. Calisto, M., Usoskin,I., Rozanov, E., Peter, T., (2011). Influence of galactic cosmic rays on atmospheric composition and dynamics, Atmos. Chem. Phys., 11, 4547-4556.

[71]. Velinov, P.I.Y., Mateev, L., (1990). Response of the middle atmosphereon galactic cosmic ray influence, Geomagn. Aeronomy, 30 (4), 593-598.

[72]. Kilifarska, N.A.,(2012). Climate sensitivity to the lower stratospheric ozone variations, J. Atmos. Sol. Terr. Phys., 90/91, 9-14.

[73]. Kilifarska, N.A., (2012). Ozone as a mediator of galactic cosmic ray influence on climate, Sun Geosphys., 7 (2), $97-102$.

[74]. Kilifarska, N.A., (2013). An autocatalytic cycle for ozone production in thelower stratosphere initiated by Galactic Cosmic rays, C.R. Acad. Bulg. Sci., 66 (2), 243-252.

[75]. Las`tovic`ka, J., Križan,P.,(2005). Geomagnetic storms, Forbush decreases of cosmic rays and total ozone at northern higher middle latitudes, J. Atmos. Sol. Terr. Phys., 67, 119-124,

[76]. Las`tovic `ka, J., Križ`an,P., (2009). Impact of strong geomagnetic storms on total ozone at southern higher middle latitudes, Stud. Geophys. Geod., 53, 151-156.

[77]. Kudela, K., Storini, M., Hofer, M.Y., Belov, A., (2000). Cosmic rays in relation to space weather, Space Sci. Rev., 93 (1-2), 153174.

[78]. Kudela, K., Mavromichalaki,H.,Papaioannou,A., Gerontidou,M., (2010).On mid-term periodicities in cosmic rays, Sol. Phys., 266, $173-180$.

[79]. Agee, E.M., Kiefer, K., Cornett,E., (2012). Relationship of lowertroposphere cloud cover and cosmic rays: an updated perspective,J. Clim., 25 (3), 1057-1060.

[80]. Keilhauer, B., Blumer,J., Engel,R., Klages, H.O., Risse,M.,( 2004).Impact of varying atmospheric profiles on extensive air shower observation: atmospheric density and primary mass reconstruction, Astropart. Phys., 22 (3-4), 249-261.

[81]. Keilhauer, B., Blumer, J., Engel,R., Klages,H.O., (2006). Impact of varying atmospheric profiles on extensive air shower observation: fluorescence light emission and energy reconstruction, Astropart. Phys., 25 (4), 259-268.

[82]. Mishev, A., Velinov,P.I.Y.,(2008). Effects of atmospheric profilevariations on yield ionization function Y in the atmosphere, C.R.Acad. Bulg. Sci., 61 (5), 639-644.

[83]. Buchvarova, M., Velinov,P.I.Y., (2010). Empirical model of cosmic ray spectrum in energy interval $1 \mathrm{MeV}-100 \mathrm{GeV}$ during $11-$ year solar cycle, J. Adv. Space Res., $45(8,1), 1026-1034$.

[84]. Buchvarova, M., Velinov, P.I.Y.,Buchvarov,I., (2011). Model approximation of cosmic ray spectrum, Planet. Space Sci., 59 (4), 355-363.

[85]. Velinov, P.I.Y., Ruder, H., Mateev,L., (2005). Analytical model forcosmic ray ionization by nuclei with charge Z in the lowerionosphere and middle atmosphere, C.R. Acad. Bulg. Sci., 58,897-902.

[86]. Velinov, P.I.Y., Mishev, A.,(2008). Solar cosmic ray induced ionizationin the Earth's atmosphere obtained with CORSIKA code simulations,C.R. Acad. Bulg. Sci., 61 (7), 927-932.

[87]. Agostinelli, S., Allison, J., Amako, K., Apostolakis, J., Araujo, H.,et al.,( 2003). GEANT 4 - a simulation toolkit, Nucl. Instrum. MethodsPhys. Res., A: Accelerators, Spectrometers, Detectors andAssociated Equipment, 506 (3), $250-303$.

[88]. Battistoni, G., Muraro, S., Sala, P. R.., Cerutti, F.,Albrow, M., Raja, R.,Ferrari, A., et al.,(2007). The FLUKA code: description and benchmarking. In Proc. of the Hadronic Shower SimulationWorkshop 2006, Fermilab 6-8 September 2006, 896: AIP Conference Proc, 31-49.

[89]. Egorova, T., Rozanov, E., Zubov, V., Manzini, E., Schmutz, W.,Peter, T., (2005). Chemistry-climate model SOCOL: a validation of the present-day climatology, Atmos. Chem. Phys., 5, 1557-1576.

[90]. Fesefeldt, H.C., GHEISHA program, Technical Report PITHA 85- 02, III Physikalisches Institut, RWTH Aachen Physikzentrum, 5100 Aachen, Germany, September, 1985.

[91]. Heck, D., Knapp, J., Capdevielle, J.N., Schatz, G., Thouw, T., (1998).CORSIKA: A Monte Carlo Code to Simulate Extensive Air Showers, forschungszentrum Karlsruhe Report FZKA 6019.

[92]. Wissing, J.M., Kallenrode, M.B., (2009). Atmospheric IonizationModule Osnabruck (AIMOS): a 3D model to determine atmosphericionization by energetic charged particles from differentpopulations, J. Geophys. Res., 114 , A06104.

[93]. Velinov, P.I.Y., Asenovski, S., Mateev, L., (2011). Simulation of cosmicray ionization profiles in the middle atmosphere and lowerionosphere on account of characteristic energy intervals, C.R.Acad. Bulg. Sci., 64 (9), 1303-1310.

[94]. Velinov, P.I.Y., Asenovski, S., Mateev, L.,(2012). Improved cosmic rayionization model for ionosphere and atmosphere (CORIMIA)with account of 6 characteristic intervals, C.R. Acad. Bulg. Sci.,65 (8), 1135-1144.

[95]. Tsagouri, I., Belehaki, A., Bergeot, N., Cid, C., Delouille, V., et al.,(2013).Progress in space weather modeling in an operational environment, J. Space Weather Space Clim., 3, in press.

[96]. Desorgher, L., Fluckiger, E., Gurtner, M., Moser, M.R., Bütikofer, R., et al., (2005). Atmocosmics: a GEANT4 code for computing the interaction of cosmic rays with the Earth's atmosphere, Int. J.Mod. Phys., A 20 (29), 6802-6804.

[97]. Cummings, A.C., Stone, E.C., Webber, W.R., (1984). Evidence that the anomalous cosmic-ray component is singly ionized, Astrophys. J., 287, 99-103.

[98]. Leske, R.A., Cummings,A.C., Mewaldt, R.A., Stone, E.C.,(2011).Anomalous and galactic cosmic rays at 1 AU during the cycle 23/24 solar minimum, Space Sci. Rev., DOI: 10.1007/s11214-011-9772-1.

[99]. McDonald, F.B., Klecker, B., McGuire, R.E., Reames, D.V., (2002).Relative recovery of galactic and anomalous cosmic rays at 1 AU: further evidence for modulation in the heliosheath, J. Geophys.Res., 107 (A8), DOI: 10.1029/2001JA000206.

[100]. Velinov, P.I.Y., (1991). Effect of the Anomalous Cosmic Ray (ACR)component on the high-latitude ionosphere, C.R. Acad. Bulg.Sci., 44 (2), 33-36,

[101]. Velinov, P.I.Y., Mishev, A., (2007). Cosmic ray induced ionization in theatmosphere estimated with CORSIKA code simulations, C.R.Acad. Bulg. Sci., 60 (5), 495-502.

[102]. Velinov, P.I.Y., Mishev, A., (2008). Cosmic ray induced ionization in theupper, middle and lower atmosphere simulated with CORSIKAcode, in Proceedings of the 30th International Cosmic RayConference, Merida, Mexico, 3-11 July 2007,1 (SH), 749752 .

[103]. Velinov, P.I.Y., Ruder, H., Mateev, L., Buchvarova, M., Kostov, V., (2004). Method for calculation of ionization profiles caused by cosmicrays in giant planet ionospheres from Jovian group, J. Adv. Space Res., 33, 232-239.

[104]. Velinov, P.I.Y., Mateev, L., Kilifarska, N.,(2005). 3D model for cosmicray planetary ionization in the middle atmosphere, Annal. Geophys., 23 (9), 3043-3046.

[105]. Velinov, P.I.Y., Ruder, H., Mateev, L.,(2006). Energy interval coupling inimproved cosmic ray ionization model with three intervals inionization losses function for the system atmosphere/ionosphere,C.R. Acad. Bulg. Sci., 59, 847-854. 
[106]. Velinov, P.I.Y., Mateev, L., Ruder, H.,(2008). Generalized model ofionization profiles due to cosmic ray particles with charge Z inplanetary ionospheres and atmospheres with 5 energy intervalapproximation of the ionization losses function, C.R. Acad. Bulg.Sci., 61 (1), 133-146.

[107]. Buchvarova, M., Velinov, P.I.Y. (2005).Modeling spectra of cosmic rays influencing on the ionospheres of earth and outer planets during solar maximum and minimum, J. Adv. Space Res., 36 (11), 2127-2133.

[108]. Usoskin, I., Kovaltsov, G., (2006). Cosmic ray induced ionization in the atmosphere: full modeling and practical applications, J. Geophys. Res., 111, D21206.

[109]. Velinov, P.I.Y., Mateev, L.,(2008). Analytical approach to cosmic rayionization by nuclei with charge $\mathrm{Z}$ in the middle atmosphere distribution of galactic CR effects, J. Adv. Space Res., 42, 1586-1592.

[110]. Velinov, P.I.Y., Mishev, A., Mateev, L., (2009). Model for inducedionization by galactic cosmic rays in the Earth atmosphere andionosphere, J. Adv. Space Res., 44, 1002-1007.

[111]. Umahi, A. E., (2016). Impact of High Energy Charged Galactic Particle Variations in the Earth's Atmosphere, Middle-East Journal of Scientific Research, 24 (5), 1788-1793. DOI: 10.5829/idosi.mejsr.2016.24.05.23456

[112]. Umahi, A. E., (2016). Effects of Cosmic Rays and Solar Flare Variations in Earth's Atmospheric Mechanism and Ionization, Middle-East Journal of Scientific Research, 24 (5), 1794-1801.DOI:10.5829/idosi.mejsr.2016.24.05.23457.

[113]. Umahi, A. E., (2016). Impact of Space Radiation in the Earth's Atmosphere, American-Eurasian J. Agric. \& Environ. Sci., 16 (5), 868-873, DOI: 10.5829/idosi.aejeas.2016.16.5.10440.

[114]. Umahi, A. E., (2016). Variability of Galactic Cosmic rays Flux and Solar Activities in the Earth's Atmospheric Environment, American-Eurasian J. Agric. \& Environ. Sci., 16 (5), 874-881, DOI: 10.5829/idosi.aejeas.2016.16.5.10441.

[115]. Brasseur, G., and S. Solomon, 2005.Aeronomy of the Middle Atmosphere,Springer, Dordrecht.

[116]. Velinov, P.I.Y., Mishev, A.,Asenovski,S., and. Mateev, L.,(2011). New operational models for cosmic ray ionization in space physics, Bulg. J. Phys., 38, 264-273

[117]. Velinov, P.I.Y., Asenovski, S., and Mateev, L., (2012). Improved cosmic ray ionization model for ionosphere and atmosphere (CORIMIA) with account of 6 characteristic intervals, $\quad$ C.R. Acad. Bulg. Sci., 65 (8), $1135-1144$.

[118]. Sternheimer, R.,1961. in Fundamental Principles and Methods of Particle Detection. Methods of Experimental Physics, vol. V, A. NuclearPhysics, edited by L.C.L., Yuan, and C.S. Wu, New York, London, Academic Press.. 